\title{
Fontes de resistência em tomateiro aos begomovírus bissegmentados Tomato yellow spot virus e Tomato severe rugose virus
}

\author{
Francisco D Hurtado'; Marta A Gili; Yamila M Zubiaur²; Jorge G Aguilera ${ }^{3}$; César Augusto D Xavier ${ }^{4}$; \\ Francisco Murilo Zerbini Junior ${ }^{4}$; Derly Jose $\mathrm{H}_{\text {da Silva }}{ }^{5}$ \\ ${ }^{1}$ INCA, Depto. Genética y Mejoramiento de Plantas, Carretera de Tapaste km 3,1/2, 32700 La Habana, Cuba; franko@inca.edu.cu; \\ malvarez@inca.edu.cu; ${ }^{2}$ CENSA, Lab. Virología Molecular de Plantas, Apartado 10, San José de Las Lajas, 32700 La Habana, Cuba, \\ yamila@censa.edu.cu; ${ }^{3}$ UFV, Progr. Pos-graduação em Genética e Melhoramento, 36570-000 Viçosa-MG, Brasil; j51173@yahoo.com; \\ ${ }^{4} \mathrm{UFV}$, Depto. Fitopatologia, cesar.xavier@ufv.br, zerbini@ufv.br; ${ }^{5} \mathrm{UFV}$, Depto. Fitotecnia; derly@ufv.br
}

\section{RESUMO}

Os begomovírus causam doenças de grande importância econômica em diversas culturas, principalmente em regiões tropicais e subtropicais. Juntamente com outras famílias de vírus, os begomovírus têm causado grande prejuízo para os produtores de tomate in natura e para processamento industrial. O objetivo deste trabalho foi avaliar o comportamento de 11 genótipos resistentes ao Tomato yellow leaf curl virus (TYLCV) frente à infecção pelos begomovírus Tomato yellow spot virus (ToYSV) e Tomato severe rugose virus (ToSRV) em condições de casa-vegetação. A inoculação das plantas foi realizada via biobalística no estádio de duas folhas verdadeiras. A infecção viral confirmou-se pelo desenvolvimento dos sintomas e pela técnica de hibridização dot blot. Selecionaram-se como promissores os genótipos STY2, STY5, STY6 e L7, por não apresentarem sintomas e por terem concentrações virais muito baixas para os dois vírus. O espectro de resistência dos genes $T y$-1 e $T y$-2 não resultaram efetivos ante as espécies virais empregadas no estudo. As linhagens TY52, H24 e CLN2116B, portadoras destes genes, foram suscetíveis aos vírus ToYSV e ToSRV.

Palavras-chave: Solanum lycopersicum, geminivírus, resistência.

\begin{abstract}
Sources of resistance in tomato to bipartite begomoviruses Tomato yellow spot virus and Tomato severe rugose virus

Begomoviruses cause diseases of major economic importance in many crops, especially in tropical and subtropical regions. Together with other families of viruses, the begomoviruses cause great damage for producers of fresh and processed tomatoes. The objective of this study was to evaluate the behavior of 11 resistant genotypes to Tomato yellow leaf curl virus (TYLCV) when infected by the begomoviruses Tomato severe rugose virus (ToSRV) and Tomato yellow spot virus (ToYSV) under greenhouse conditions. Tomato plants were inoculated by biobalistic method when displaying two true leaves. Viral infection was confirmed by visual observation of symptoms and by dot blot hybridization. Genotypes STY2, STY5, STY6 and L7 were selected as promising due to the absence of symptoms and very low viral concentration for both viruses. The resistance genes $T y-1$ and $T y-2$ were not effective against the viral species used in the study. The lines TY52, H24 and CLN2116B, carrying these genes, exhibited a susceptible behavior.
\end{abstract}

Keywords: Solanum lycopersicum, geminivirus, resistance.

\section{(Recebido para publicação em 14 de junho de 2011; aceito em 3 de agosto de 2012)} (Received on June 14, 2011; accepted on August 3, 2012)

$\mathrm{N}$ o Brasil e demais países produtores de tomate (Solanum lycopersicum), seu cultivo durante todo o ano propicia condições favoráveis ao surgimento de doenças causadas por bactérias, fungos e, principalmente, por vírus (Matos et al., 2003).

Os vírus pertencentes à família Geminiviridae caracterizam-se pela morfologia de partículas icosaédricas geminadas e genoma composto por uma ou duas moléculas de DNA de fita simples circular com aproximadamente 2.500 a 3.000 nucleotídeos. A família está dividida em quatro gêneros (Curtovirus, Topocuvirus, Mastrevirus e Begomovírus), dependendo da organização do genoma, tipo de inseto vetor e gama de hospedeiros. Dentro desta família o gênero Begomovírus inclui vírus que são transmitidos por "mosca-branca" (Bemisia tabaci), infectam plantas dicotiledôneas e possuem genoma mono ou bissegmentado (Navas et al., 2011). Os begomovírus, juntamente com os tospovírus (transmitidos por tripes e que causam a doença conhecida no Brasil como "vira-cabeça"), têm causado grande prejuízo para os produtores de tomate in natura e para processamento industrial.

O primeiro relato de begomovírus no Brasil ocorreu na década de 1970
(Costa, 1976). O agente etiológico foi posteriormente caracterizado e denominado Tomato golden mosaic virus (TGMV). Além do TGMV, cinco outros virus transmitidos por mosca-branca foram identificados, porém sem causar danos de importância econômica na cultura (Matyis et al., 1975). Na época, a incidência do vírus foi atribuída à migração do vetor a partir de plantas de soja (Glycine max) e feijão (Phaseolus vulgaris), e à existência de reservatórios naturais do vírus. Entretanto, a doença foi considerada de importância secundária, provavelmente devido à baixa adaptabilidade do biótipo A de $B$. tabaci, então predominante no país, as 
solanáceas.

Durante a década de 90, o biótipo B de B. tabaci foi introduzido no Brasil. Em oposição ao biótipo A, o biótipo B coloniza o tomateiro e outras solanáceas com grande eficiência, e à sua rápida disseminação pelo país seguiram-se vários relatos de infecção de begomovírus em tomateiro. No estado de Minas Gerais, em 1996, foi relatada a incidência de begomovírus em tomateiro nas localidades de Uberlândia e Igarapé, regiões distantes mais de $500 \mathrm{~km}$ entre si (Rezende et al., 1996).

Desde 1994, dezesseis novas espécies de begomovírus, todas com genoma bissegmentado, já foram descritas infectando tomateiro no Brasil (Calegario et al., 2007). Progressos consideráveis já foram realizados na identificação e caracterização biológica-molecular dos vírus que ocorrem nas principais regiões produtoras. Este fato contribuiu para que aumentassem os esforços na procura de materiais resistentes, como a forma mais racional de se combater o aumento da incidência e da severidade das infecções por begomovírus em tomateiro no Brasil.

Pelo menos nos últimos 15 anos, o Tomato severe rugose virus (ToSRV) é uma das espécies de begomovírus que mais infecta as plantas da família solanácea no Brasil (Barbosa et al., 2011). Segundo Fernandes et al. (2008), o ToSRV é uma das espécies virais de maior prevalência nas regiões produtoras de tomate no país. Por outro lado, o Tomato yellow spot virus (ToYSV) é um dos begomovírus mais agressivos dentre os que afetam a cultura do tomateiro caracterizado pela severidade e precocidade de seus sintomas, ainda que se desconhecem estudos que quantifiquem os danos que ele causa (Ambrozevicius et al., 2002). A procura e identificação de fontes de resistências a estes dois begomovírus são pesquisas que devem ser priorizadas, considerando a distribuição desses dois vírus e os danos que eles ocasionam na cultura do tomateiro.

Atualmente, muitas introgressões gênicas em cultivares vêm sendo realizadas com os genes Ty-1 (Zamir et al., 1994) e Ty-2 (Hanson et al., 2006), com alto nível de resistência ao begomovírus monossegmentado Tomato yellow leaf curl virus (TYLCV) (Ji et al., 2009), o principal (e em alguns casos o único) begomovírus que infecta o tomateiro em países do Mediterrâneo, Oriente Médio, América do Norte e Caribe (Hanssen et al., 2010), mas que não ocorre no Brasil (Aguilera et al., 2011).

A partir desses antecedentes, a presente pesquisa teve como objetivo avaliar a resistência de genótipos de tomateiro de diferentes origens com resistência a TYLCV, abrangendo cultivares e linhagens portadoras dos genes Ty-1 e Ty-2, frente a isolados dos begomovírus bissegmentados Tomato yellow spot virus e Tomato severe rugose virus.

\section{MATERIAL E MÉTODOS}

Os experimentos foram desenvolvidos de janeiro a maio de 2010 , no Departamento de Fitopatologia da Universidade Federal de Viçosa, avaliando-se um total de treze genótipos, todos pertencentes à espécie Solanum lycopersicum (Tabela 1).

Cinco plantas por genótipo foram inoculadas via biobalistica (Aragão et al., 1996), no estado vegetativo de duas folhas verdadeiras. Uma planta de cada genótipo foi inoculada apenas com partículas de tungstênio, como controle sadio. Os genótipos Campbell 28 e Débora foram empregados como controles suscetíveis aos isolados virais de ToYSV e ToSRV.

As plantas inoculadas foram transplantadas para vasos de 1 L de capacidade que continham um substrato composto por uma mistura de terra e esterco bovino em uma proporção $3: 1$, previamente esterilizado. As plantas foram mantidas em ambiente protegido por 30 dias após a inoculação (dpi) para a observação e avaliação dos sintomas. $\mathrm{O}$ experimento foi conduzido em delineamento inteiramente casualizado com 13 tratamentos (os genótipos) e cinco repetições (cada planta individual).

Para o estudo utilizaram-se os isolados virais Bi2 do ToYSV (Ambrozevicius et al., 2002), obtidos a partir de uma planta de tomateiro coletada no município de São Joaquim de Bicas, na Zona Metalúrgica de Minas Gerais e BR:Pir1:05 do ToSRV
(Martins, 2008), obtido em 2005 a partir de uma planta de tomateiro coletada na região de Piraju-SP. Esses isolados encontram-se disponíveis na forma de clones infecciosos, denominados pToYSV-A1.2 e pToYSV-B1.2 (ToYSV DNA-A e DNA-B, respectivamente) e pVIR096 e pVIR97 (ToSRV DNA-A e DNA-B, respectivamente). A inoculação realizou-se empregando $2 \mu \mathrm{g}$ de cada componente genômico (DNA-A e DNA-B).

Para avaliar a severidade dos sintomas utilizou-se a escala de notas descrita por Giordano et al. (2005a), adaptada aos sintomas característicos de cada vírus: a) ToYSV (0: sem sintomas; 1 : manchas cloróticas e epinastia; 2 : mosaico severo, epinastia, distorção foliar e redução de crescimento); b) ToRSV (0: sem sintomas; 1: amarelecimento e enrugamento dos folíolos; 2: mosaico, clorose, deformação foliar e redução de crescimento).

Para determinar a presença e a concentração do DNA viral utilizou-se a técnica de hibridação de ácidos nucléicos (HAN) do tipo não radioativa (Quiñones et al., 2007), mediante o procedimento de dot blot. O DNA-A total dos clones virais pToYSV-A1.2 e pVIR096 foi empregado como sonda, sendo posteriormente marcados com digoxigenina segundo o protocolo proposto pela Roche Diagnostics (DIG High Prime DNA Labeling and Detection Kit).

O DNA total das plantas inoculadas (cinco de cada cultivar) e não inoculadas (uma de cada cultivar) foi extraído segundo Dellaporta et al. (1983), a partir de um disco de $6 \mathrm{~mm}$ de diâmetro, que foi coletado das folhas apicais no mesmo momento em que foram realizadas as avaliações de severidade (30 dpi). Um total de $100 \mu \mathrm{L}(50 \mu \mathrm{L}$ de DNA extraído e $50 \mu \mathrm{L}$ de solução de SSC 16X e formaldeido 7,5\%), foram aplicados sobre as membranas de nylon carregadas positivamente (Hybond-N+, GE Healthcare) com auxilio de uma micropipeta, em condições de vácuo. A fixação do DNA foi realizada irradiando-se as membranas com luz ultravioleta $\left(120 \mathrm{~mJ} / \mathrm{cm}^{2}\right)$ por 1 minuto, com o auxílio do aparelho UV-crosslinker $(\mathrm{E}=$ $120 \mathrm{~mJ} / \mathrm{cm}^{2}$ ) (Amersham Pharmacia Biotech, Reino Unido). 
A hibridização foi realizada a $42^{\circ} \mathrm{C}$ por 16 horas seguida de duas lavagens à temperatura ambiente em SSC $0,5 \mathrm{X}$ e SDS $0,1 \%$ por 5 minutos cada uma e outras duas lavagens a $65^{\circ} \mathrm{C}$ em SSC $0,1 \mathrm{X}$ e SDS $0,1 \%$ por 15 minutos cada uma. As membranas foram incubadas por 30 minutos com solução de bloqueio seguido de incubação por 30 minutos na solução de anticorpo. Foram realizadas duas lavagens de 15 minutos em ácido maleico 0,1M pH 7,5, $\mathrm{NaCl} 0,15$ M, Tween 20 0,3\%. Para a revelação acrescentou-se o substrato CSPD em tampão de revelação (Tris- $\mathrm{HCl}$ 0,1 M, $\mathrm{NaCl}$ 0,1 M, $\mathrm{MgCl}_{2} 50$ mM, pH 9,5), incubando-se por 5 minutos à temperatura ambiente. Posteriormente foi eliminado o excesso de líquido e as membranas foram incubadas a $37^{\circ} \mathrm{C}$ por 10 minutos. A exposição a filmes de raios X (Kodak $\mathrm{X}$-OMAT) foi por 20 minutos.

Foram acrescentados como controle, em cada membrana, DNA de plantas sadias (não inoculadas), água milli-Q e DNA de planta infectada com uma quantidade pré-determinada de $100 \mathrm{ng} \mu \mathrm{L}^{-1}$ de DNA viral. Para melhor interpretação dos resultados utilizou-se a seguinte escala: 0: sem detecção do DNA viral; 1: detecção do DNA viral em quantidade inferior a $100 \mathrm{ng} \mu \mathrm{L}^{-1}$; 2: detecção do DNA viral em quantidade igual a 100 ng $\mu \mathrm{L}^{-1}$ e 3 : detecção do DNA viral em quantidade superior a $100 \mathrm{ng} \mu \mathrm{L}^{-1}$.

Foram classificados como promissores os acessos cujas notas foram iguais a 0 (zero) para a avaliação de sintomas e 0 (zero) ou 1 (um) para a carga viral.

\section{RESULTADOS E DISCUSSÃO}

Os genótipos empregados como controles suscetíveis Campbell 28 e Débora desenvolveram os sintomas típicos da doença (amarelecimento, encrespamento, clorose internerval, mosaico acentuados e enrugamento, redução e deformação dos folíolos, além de redução de crescimento), os quais corresponderam aos valores máximos de severidade e de carga viral (Tabela 2), o que confirmou a efetividade da inoculação com ambos begomovírus e o emprego acertado dos controles suscetíveis para esta doença.

A rapidez na aparição dos sintomas e a determinação de concentração superiores a 100 ng de DNA viral, confirmou a ausência de barreiras do tipo resistência ao ToYSV e ao ToSRV nesses dois genótipos suscetíveis, as quais segundo Gómez et al. (2009) se ativam nos momentos iniciais da inoculação e atuam em diferentes níveis na célula, entre células e a longa distância pelos tecidos condutores.

Surpreendentemente, os mesmos níveis de suscetibilidade e carga viral elevados foram observados para o genótipo PIMHIR, identificado na França como fonte de resistência ao TYLCV e que tem sido empregado nos programas de melhoramento genético desenvolvidos por grupos de pesquisa na Espanha (Pérez de Castro et al., 2007). Portanto, os mecanismos relacionados à resistência a um dos vírus mais agressivos para o cultivo do tomateiro, o TYLCV, não foram efetivos para os vírus testados ToSRV e ToYSV nas condições deste experimento.

Os genótipos H24 e CLN2116B, portadores do gene $T y$-2, também foram descartados em função da suscetibilidade aos dois vírus. A presença do gene Ty-2 confere tolerância a alguns isolados de TYLCV presentes em diferentes países, incluindo Taiwan, Vietnam, sul da Índia e Israel, porem não é efetiva a isolados do norte da Índia, Tailândia, Filipinas e da América Central. Não obstante, a linhagem H24, contendo o gene $T y$-2, tem sido empregada em programas de melhoramento genético do tomateiro no AVRDC de Taiwan (Hanson et al., 2006).

O caráter suscetível de H24 também foi observado ao ser utilizado na procura de novas fontes de resistência a begomovírus presentes na Guatemala (Mejía et al., 2005). Esta linhagem foi também suscetível quando a inoculação foi mediada pelo inseto vetor e via agroinoculação na seleção de subamostras de Solanum frente ao begomovírus Tomato leaf curl virus (ToLCV) (Tripathi \& Varma, 2002) e Tomato leaf curl virus (TLCV) (Bian et al., 2007).

Diferentemente, a subamostra L7, que também contém o gene $T y$ - 2 , foi selecionada como resistente com base na ausência de sintomas e carga viral reduzida. O comportamento resistente de L7 ante os vírus ToYSV e ToSRV poderia ser explicado por ter sido selecionada como resistente aos begomovírus presentes em diferentes regiões produtoras da Nicarágua (Poikela et al., 2005), onde prevalecem begomovírus com genomas bissegmentados relacionados aos que ocorrem no Brasil (Fauquet et al., 2008). Esta resistência possivelmente está relacionada a mecanismos distintos daqueles associados ao gene $T y-2$.

Por outro lado, Jiménez et al. (2010) descreveram que o L7 teve sua origem a

Tabela 1. Germoplasma vegetal utilizado para a pesquisa (plant germplasm used in this research). Viçosa, UFV, 2010.

\begin{tabular}{ll}
\hline Genótipos & \multicolumn{1}{c}{ Fonte de resistência } \\
\hline CLN2116B & Ty-2 a partir de Solanum lycopersicum (H24) \\
H24 & Ty-2 a partir de S. habrochaites (B6013) \\
L7 & Ty-2 a partir de S. lycopersicum (H24) \\
PIMHIR & S. pimpinellifolium \\
STY2 & S. lycopersicum híbrido 8484 (Hazera Genetics) \\
STY3 & S. lycopersicum híbrido Fiona (S\&G, Enkhuizen, Holanda) \\
STY5 & S. lycopersicum híbrido Tyking (Royal Sluis, Enkhuizen, Holanda) \\
STY6 & S. peruvianum (PI 126930, PI 390681 e LA 441) \\
STY7 & S. peruvianum (PI 126930, PI 390681 e LA 441) \\
TY52 & Ty-1 a partir de S. chilense (LA 1969) \\
Vyta & Ty-1 a partir de S. chilense (LA 1969) \\
Campbell 28 & \\
Débora $^{1}$ &
\end{tabular}

${ }^{1}$ Genótipos utilizados como controles suscetíveis (susceptible genotypes used as controls). 
Tabela 2. Reação dos genótipos avaliados após inoculação com os begomovírus bissegmentados Tomato severe rugose virus (ToSRV) e Tomato yellow spot virus (ToYSV) (reaction of genotypes after inoculation with the bipartite begomoviruses Tomato severe rugose virus (ToSRV) and Tomato yellow spot virus (ToYSV)). Viçosa, UFV, 2010.

\begin{tabular}{lccccc}
\hline \multirow{2}{*}{ Genótipos } & \multicolumn{2}{c}{ ToYSV } & & \multicolumn{2}{c}{ ToSRV } \\
\cline { 2 - 3 } \cline { 5 - 6 } & $\begin{array}{c}\text { Severidade } \\
\text { de sintomas }^{1}\end{array}$ & $\begin{array}{c}\text { Carga }_{\text {viral }^{2}} \\
\text { CLN2116B }\end{array}$ & & $\begin{array}{c}\text { Severidade } \\
\text { de sintomas }\end{array}$ & Carga viral \\
\hline H24 & 1,4 & 1,2 & & 1,0 & 1,4 \\
L7 & 1,8 & 2,0 & & 1,4 & 1,8 \\
PIMHIR & 0,0 & 0,6 & & 0,0 & 1,4 \\
STY2 & 1,0 & 2,4 & & 1,0 & 2,2 \\
STY3 & 0,6 & 1,0 & & 0,0 & 1,2 \\
STY5 & 0,4 & 1,2 & & 1,2 & 2,0 \\
STY6 & 0,0 & 0,8 & & 0,0 & 1,2 \\
STY7 & 0,0 & 1,4 & & 0,0 & 1,4 \\
TY52 & 0,4 & 0,8 & & 1,2 & 2,2 \\
Vyta & 1,2 & 2,0 & & 1,8 & 1,6 \\
Campbell 28 & $0,0^{3}$ & 0,0 & & 0,8 & 1,0 \\
Débora & 1,6 & 2,4 & & 1,2 & 1,4 \\
\hline
\end{tabular}

${ }^{1}$ Sintomas avaliados com base na escala de notas descrita por Giordano et al. (2005a) adaptada aos sintomas induzidos pelos vírus ToYSV $(0=$ sem sintomas; $1=$ manchas cloróticas e epinastia; 2 = mosaico severo, epinastia, distorção das folhas, foliar e redução do crescimento) e ToRSV $(0=$ sem sintomas; $1=$ amarelecimento e enrugamento dos folíolos; $2=$ mosaico, cloroses, deformação foliar e redução do crescimento, deformação foliar); ${ }^{2}$ Carga viral avaliada com base em escala de notas $(0=$ sem detecção do DNA viral; $1=$ detecção do DNA viral em quantidade inferior a $100 \mathrm{ng} \mu \mathrm{L}^{-1} ; 2=$ detecção do DNA viral em quantidade igual a $100 \mathrm{ng}$ $\mu \mathrm{L}^{-1} ; 3=$ detecção do DNA viral em quantidade superior a $\left.100 \mathrm{ng} \mu \mathrm{L}^{-1}\right) ;{ }^{3}$ Valores referentes à média de cinco plantas, aos $30 \mathrm{dpi}\left({ }^{1}\right.$ symptoms assessed based on the rating scale described by Giordano et al. (2005a) adapted to the symptoms induced by the viruses ToYSV $(0=$ no symptoms; $1=$ chlorotic spots and epinasty; $2=$ severe mosaic, epinasty, leaf distortion and reduction of leaf growth $)$ and ToRSV $(0=$ no symptoms; $1=$ yellowing and wrinkling of the leaflets; $2=$ mosaic, chlorotic, leaf distortion, reduction of growth and leaf deformation); ${ }^{2}$ viral load evaluation based on rating scale $(0=$ no detection of viral DNA; $1=$ less than 100 ng $\mu \mathrm{L}^{-1}$ of viral DNA; $2=$ detection of $100 \mathrm{ng} \mu \mathrm{L}^{-1}$ of viral DNA; $3=$ detection of more than $100 \mathrm{ng} \mu \mathrm{L}^{-1}$ of viral DNA); ${ }^{3}$ Values corresponding to an average of five plants at $30 \mathrm{dpi}$ ).

partir de dois parentais cuja resistência foi introduzida a partir de origens diferentes. De acordo com estes autores, o L7 foi produto do cruzamento entre as linhagens FLA478-6-1-11 e CLN2498C. A primeira delas (FLA478-6-1-11), portadora da resistência do acesso LA1938 de S. chilense (Bian et al., 2007) com um comportamento resistente frente aos begomovírus Tomato mottle virus (ToMoV), Tomato yellow mosaic virus (ToYMV) (bissegmentados, do Novo Mundo) e Tomato yellow leaf curl virus (monossegmentado, do Velho Mundo) (Ji et al., 2007a; Martínez et al., 2008). Porém, a segunda (CLN2498C) é portadora do gene $T y-2$ de resistência a begomovírus, introduzido a partir da (um processo que é regulado de forma distinta em begomovírus monossegmentados e bissegmentados) (Matos et al., 2003), comportando-se de forma mais eficiente em condições de baixo potencial de inóculo (Zamir et al., 1994). A cv. Vyta e a linhagem TY52 são portadoras deste gene. Entretanto, em relação ao ToSRV e ToYSV, Vyta apresentou comportamento resistente, enquanto TY52 foi suscetível. Os resultados obtidos indicam que o gene $T y-1$ em TY52 não foi eficiente para evitar os efeitos da multiplicação e indução de sintomas pelos dois vírus. Estes resultados estão em consonância com os obtidos na triagem e seleção de fontes de resistência frente à begomovírus bissegmentados presentes no Brasil e na Guatemala (Santana et al., 2001; Mejía et al., 2005).

Pesquisadores da Embrapa Hortaliças, em estudos realizados com híbridos portadores do gene $T y$-1, detectaram comportamento tolerante ante a infecção provocada por dois begomovírus bissegmentados, Tomato rugose mosaic virus (ToRMV) e Tomato yellow veink streak virus (ToYVSV) (Boiteux et al., 2007). Selecionando novas fontes de resistência ao ToYVSV, Matos et al. (2003), observaram resistência intermediária de linhagens segregantes para o gene $T y-1$ quando inoculadas por mosca-branca.

O comportamento da cv. Vyta poderia estar relacionado à presença de outros mecanismos de resistência incorporados durante sua obtenção, pois na genealogia empregou-se o híbrido Tyking (Piñón, 2009), do qual se obteve uma linhagem resistente cuja fonte é o loco $\mathrm{tcm}-1$, um gene recessivo que confere resistência apenas em condição de homozigose (Giordano et al., 2005b).

Essa hipótese é reforçada pelos resultados obtidos com a linhagem STY5, que também tem sua origem em Tyking. Essa linhagem não apresentou os sintomas característicos de infecção e a carga viral, para ambos os vírus, sendo a carga viral inferior a $100 \mathrm{ng} \mu \mathrm{L}^{-1}$. Portanto, o gene $t \mathrm{~cm}-1$ parece ser um bom candidato a fonte de resistência de amplo espectro a begomovírus bissegmentados do Brasil, uma vez que já foi demonstrado ser eficiente contra o ToCMoV (Santana et al., 2001) e parece ser eficiente também contra o ToSRV e o ToYSV. 
Trabalhos adicionais, direcionados especificamente ao gene $t \mathrm{~cm}-1$, serão necessários para se comprovar essa hipótese. Nesse sentido, é relevante mencionar que outras pesquisas realizadas com diferentes subamostras do Banco de Germoplasma de Hortaliças da UFV, avaliadas frente à infecção pelo ToYSV, indicaram a existência de resistência que poderia ser mediada por um gene recessivo (Aguilera, 2007).

Numerosos trabalhos têm descrito comportamento resistente de subamostras obtidas a partir da espécie silvestre $S$. peruvianum ante diferentes isolados de begomovírus (Lapidot et al., 2006). As subamostras STY6 e STY7 originadas desta espécie apresentaram respostas distintas frente aos dois vírus testados. O caráter resistente do STY6 já havia sido descrito ante outros begomovírus bissegmentados presentes no Brasil (Santana et al., 2001; Giordano et al., 2005b) e na Guatemala (Mejía et al., 2005).

O comportamento resistente do STY2, frente ao ToYSV e ToSRV, mostrou o amplo espectro de resistência, desse genótipo, ante ambas espécies virais, ao mesmo tempo em que STY3 e STY7 somente foram à espécie ToYSV. Nesse sentido, Ji et al. (2007a) descreveram respostas diversas e não específicas que têm apresentado diferentes fontes de resistência a begomovírus em tomate, ante diferentes espécies do gênero a que foram sobmetidas e em diferentes agro-ambientes onde foram avaliadas.

Atualmente, a liberação de cultivares ou híbridos de tomateiro sem resistência a begomovírus é uma opção arriscada, devido à ampla disseminação e agressividade que possuem estes fitopatógenos em todas as regiões do Brasil onde se cultiva essa hortaliça. A ocorrência frequente de recombinação e pseudo-recombinação entre begomovírus (Silva et al., 2011), levando ao surgimento de novas espécies (Navas et al., 2011), e à introdução de outras pragas quarentenárias nos agro-ecosistemas, são aspectos que devem ser levados em consideração pelos pesquisadores em virtude do uso adequado e aproveitamento dos recursos genéticos presentes em bancos de germoplasma ou coleções de trabalho.

Com base nos resultados obtidos na avaliação das diferentes fontes de resistências a begomovírus, é possível concluir que as subamostras STY2, STY5, STY6 e L7 possuem comportamento promissor ante os dois begomovírus testados. As subamostras TY52, H24 e CLN2116B, portadoras dos genes Ty-1 e Ty-2, comportaram-se como genótipos suscetíveis aos begomovírus ToYSV e ToSRV.

\section{AGRADECIMENTOS}

À CAPES pelo financiamento para realizar as pesquisas no Brasil a partir do projeto de cooperação bilateral CAPES-MES 067/09, e aos Drs. Moshe Lapidot, Peter Hanson e María José Díez Niclós pelo envio das sementes de alguns dos materiais vegetais utilizados neste estudo. Os autores Francisco D Hurtado e Jorge G Aguilera agradecem pelas bolsas de estudo concedidas pela CAPES e FAPEMIG, respectivamente.

\section{REFERÊNCIAS}

AGUILERA JG. 2007. Variabilidade molecular e resistência a geminivirus em acessos de tomateiro do BGH-UFV. Viçosa: UFV. 65p (Tese mestrado).

AGUILERA JG; HURTADO FD; XAVIER CAD; LAURINDO BS; NICK C; GIL MA; SILVA DJH; ZERBINI FM. 2011. Identificação dos genes $T y-2$ e $T y-3$ de resistência a begomovírus em genótipos de tomateiro. Pesquisa Agropecuária Brasileira 46: 772-775.

AMBROZEVICIUS LP; CALEGARIO RF; FONTES EPB; CARVALHO MG; ZERBINI FM. 2002. Genetic diversity of begomoviruses infecting tomato and associated weeds in Southeastern Brazil. Fitopatologia Brasileira 27: 372-377

ARAGÃO FJL; BARROS LMG; BRASILEIRO ACM; RIBEIRO SG; SMITH FD; SANFORD JC; FARIA JC; RECH EL. 1996. Inheritance of foreign genes in transgenic bean (Phaseolus vulgaris $L$.) co-transformed via particle bombardment. Theoretical and Applied Genetics 93: 142-150.

BARBOSAJC; BARRETO SS; INOUE-NAGATA AK; REZENDE JAM. 2011. Characterization and experimental host range of a Brazilian tomato isolate of Tomato severe rugose virus. Journal of Phytopathology 159: 644-646.

BIAN XY; THOMAS MR; RASHEED MS; SAEED M; HANSON P; BARRO PJ; REZAIAN MA. 2007. A recessive allele (tgr-1) conditioning tomato resistance to geminivirus infection is associated with impaired viral movement. Phytopathology 97: 930-937.
BOITEUX LS; OLIVEIRA VR, SILVA CH; MAKISHIMA N; INOUE-NAGATA AK; FONSECA MEN; GIORDANO LB. 2007. Reaction of tomato hybrids carrying the $T y-1$ locus to Brazilian bipartite begomovírus species. Horticultura Brasileira 25: 20-23.

CALEGARIO RF; SIQUEIRASF; CHUMBINHO EA; MURILO FZ. 2007. Characterization of Tomato yellow spot virus, a novel tomatoinfecting begomovírus in Brazil. Pesquisa Agropecuária Brasileira 42: 1335-1343.

COSTA AS. 1976. Whitefly-transmitted plant diseases. Annual Review of Phytopathology 14: 429-449.

DELLAPORTA SL; WOOD J; HICKS JB. 1983. A plant DNA minipreparation: Version II. Plant Molecular Biology Reporter 1: 19-21.

FAUQUET CM; BRIDDON RW; BROWN JK; MORIONES E; STANLEY J; ZERBINI FM; ZHOU X. 2008. Geminivirus strain demarcation and nomenclature. Archives of Virology 153:783-821.

FERNANDES FR; ALBUQUERQUE LC; GIORDANO LB; BOITEUX LS; ÁVILAAC; INOUE AK. 2008. Diversity and prevalence of Brazilian bipartite begomovírus species associated to tomatoes. Virus Genes 36: 251-258.

GIORDANO LB; FONSECA MEN; SILVA JBC; INOUE-NAGATAAK; BOITEUX LS. 2005a. Efeito da infecção precoce por begomovírus com genoma bipartido em características de frutos de tomate industrial. Horticultura Brasileira 23: 815-818.

GIORDANO LB; SILVA-LOBO VL; SANTANA FM; FONSECA MEN; BOITEUX LS. 2005 b. Inheritance of resistance to the bipartite Tomato chlorotic mottle begomovirus derived from Lycopersicon esculentum cv. 'Tyking'. Euphytica 143: 27-33.

GÓMEZ P; RODRÍGUEZ AM; MOURY B; ARANDA MA. 2009. Genetic resistance for the sustainable control of plant virus diseases: breeding, mechanisms and durability. European Journal of Plant Pathology DOI 10.1007/s10658-009-9468-5

HANSON PM; GREEN SK; KUO G. 2006. $T y$-2, a gene on chromosome 11 conditioning geminivirus resistance in tomato. Rep. Tomato Genet. Coop. 56: 17-18.

HANSSEN IM; LAPIDOT M; THOMMA BPHJ. 2010. Emerging viral diseases of tomato crops. Molecular Plant-Microbe Interactions 23: 539-548.

JI YF; SCHUSTER DJ; SCOTT JW. 2007b. Ty-3, a begomovírus resistance locus near the Tomato yellow leaf curl virus resistance locus $T y-1$ on chromosome 6 of tomato. Molecular Breeding 20: 271-284.

JI YF; SCOTT JW; HANSON P; GRAHAM E; MAXWELL DP. 2007a. Sources of resistance, inheritance, and location of genetic loci conferring resistance to members of the tomato-infecting begomovíruses. En: Czosnek $\mathrm{H}$ (ed) Tomato yellow leaf curl virus disease: management, molecular biology and breeding for resistance. Springer, Dodrecht. P.343-362.

JI YF; SCOTT JW; MAXWELL D; SCHUSTER D. 2009. Molecular mapping of $T y-4$, a new 
tomato yellow leaf curl virus resistance locus on chromosome 3 of tomato. Journal of the American Society for Horticultural Science 134: 281-288.

JIMÉNEZ E; GUTÉRREZ W; GONZÁLEZ

E. 2010. Evaluación de cuatro variedades de tomate industrial (S. lycopersicum L) en el rendimiento y tolerancia al complejo mosca blanca (Bemisia tabaci Gennadius)Geminivirus. La Calera. Agronomía UNA. p. 5-15. Disponível em: http://www.una. edu.ni/diep/calera/dowload pdf/Calera InvCAL93_Num-_Ano-2010.pdf

LAPIDOT M; BEN-JOSEPH R; COHEN L; MACHBASHZ; LEVY D. 2006. Development of a scale for evaluation of Tomato yellow leaf curl virus resistance level in tomato plants. Phytopathology 96: 1404-1408.

MARTÍNEZ AK; MORALES FJ; VALLEJO FA. 2008. Caracterización molecular de un begomovírus del tomate en el Valle del Cauca, Colombia, y búsqueda de fuentes de resistencia para el mejoramiento de la variedad Unapal Maravilla. Acta Agronómica 57: 167-173.

MARTINS AT. 2008. Caracterização de dois begomovirus (Tomato severe rugose virus e Tomato yellow vein streak virus) que infectam tomateiro e obtenção de clones infecciosos. Viçosa: UFV. 86p (Tese mestrado).

MATOS ES; SIQUEIRA WJ; LOURENÇÃO AL; MELO AMT; SAWAZAKI HE; SOUZA-DIAS JAC; COLARICCIO A. 2003. Resistência de genótipos de tomateiro a um isolado de geminivírus do cinturão verde de Campinas, São Paulo. Fitopatologia Brasileira
28: $159-165$.

MATYIS JC; SILVA DM; OLIVEIRA AR; COSTA AS. 1975. Purificação e morfologia do vírus do mosaico dourado do tomateiro. Summa Phytopathologica 1: 267-275.

MEJÍA L; TENI RE; VIDAVSKI F; CZOSNEK H; LAPIDOT M; NAKHLAMK; MAXWELL DP. 2005. Evaluation of tomato germplasm and selection of breeding lines for resistance to begomovíruses in Guatemala. Acta Horticulturae 695: 251-255.

NAVAS J; FIALLO E; SÁNCHEZ, S. 2011. Emerging virus diseases transmitted by whiteflies. Annual Review of Phytopathology 49: 15.1-15.30.

PÉREZ DE CASTRO A; DIEZ MJ; NUEZ F. 2007. Inheritance of Tomato yellow leaf curl virus resistance derived from Solanum pimpinellifolium UPV 16991. Plant Disease 91: 879-885.

PIÑÓN M. 2009. Obtención de líneas de tomate (Solanum lycopersicum L.) resistentes al virus del encrespamiento amarillo de la hoja del tomate (TYLCV) en Cuba. La Havana: Instituto de Investigaciones Hortícolas Liliana Dimitrova (IIHLD), Cuba. 126p (Tese doutorado).

POIKELA M; SVENSSON E; ROJAS A; HORKO T; PAULIN L; VALKONEN JPT; KAVARNHEDEN. 2005. Genetic diversity and mixed infections of begomovíruses infecting tomato, peper and cucurbit crops in Nicaragua. Plant Pathology 54: 448-459.

QUIÑONES M; FONSECA D; MARTÍNEZ Y. 2007. Caracterización molecular de aislados de campo del virus del encrespamiento amarillo de la hoja del tomate (TYLCV). Protección Vegetal 22: 47-56.

REZENDE EA; FILGUEIRAFAR; ZERBINIFM; MACIEL-ZAMBOLIM E; FERNANDES JJ; GILBERTSON RL. 1996. Tomato infected with geminivirus in greenhouse conditions at Uberlândia-MG, Brasil. Fitopatologia Brasileira 21: 424.

SANTANA FM; RIBEIRO SG; MOITA AW; MOREIRA DJ; GIORDANO LB. 2001. Sources of resistance in Lycopersicon spp. to a bipartite whitefly-transmitted geminivírus from Brazil. Euphytica 122: 45-51.

SILVA SJC; CASTILLO GP; HORA BT; ASSUNÇAO IP; LIMA GSA; RIBEIRO G; MIZUBUTI ESG; ZERBINI FM. 2011. Species diversity, phylogeny and genetic variability of begomovírus populations infecting leguminous weeds in northeastern Brazil. Plant Pathology Doi: 10.1111/j.13653059.2011.02543.x

TRIPATHI S; VARMA A. 2002. Identification of sources of resistance in Lycopersicon species to Tomato leaf curl geminivirus (ToLCV) by agroinoculation. Euphytica 129: 43-52.

ZAMIR D; EKSTEIN-MICHELSON I; ZAKAY Z; NAVOT N; ZEIDAN M; SARFATTI M; ESHED Y; HAREL E; PLEBAN T; VAN-OSS H; KEDAR N; RABINOWITCH HD; CZOSNEK H. 1994. Mapping and introgression of a tomato yellow leaf curl virus tolerance gene, Ty-1. Theoretical and Applied Genetics 88: 141-146. 